\title{
Phenotypic plasticity and development of cold-season insects (Coleoptera: Leiodidae) and their response to climatic change
}

\author{
WERNER TOPP \\ Department of Zoology, University of Cologne, D-50923 Köln, Germany; e-mail: w.topp@uni-koeln.de
}

Key words. Life history, distributional range, circannual development, homeostasis, bet-hedging, Pleistocene

\begin{abstract}
Cold-season beetles, Catops nigricans Spence, Choleva agilis Illiger and Choleva elongata Payk., i.e. beetles which start to lay eggs in autumn, which are active during the winter in the adult stage and develop from the egg stage to the adult stage mainly during the winter months, were collected from various locations in north-western Europe and reared in the laboratory at varying temperatures and photoperiods.

Reproduction of all species started in autumn and continued during the winter months. Highest reproductive and survival rates occurred at low temperatures and within a small thermal window ranging from $5^{\circ}$ to $10^{\circ} \mathrm{C}$ : The fitness of individuals decreased at higher and lower temperatures. The lower thermal threshold for all developmental stages was in the range from $-5^{\circ} \mathrm{C}$ to $+2^{\circ} \mathrm{C}$. The metabolisms of the species were independent of temperature in both dormant and non-dormant stages and were elevated in the low temperature range in comparison to other species which show a temperature-dependent reaction pattern.

Optimal dates for reproduction were determined by the duration of an obligatory adult summer diapause. In C. nigricans, which favours the litter layer of deciduous forests, this duration was fine-tuned by exogenic factors, such as photoperiod and temperature. In contrast, the soil-inhabiting species Ch. elongata showed a homeostatic response pattern, independent of temperature and photoperiod. Heritability $\left(\mathrm{h}^{2}\right)$ of the duration of diapause was approximately 0.26 in C. nigricans, less pronounced in Ch. agilis (ca. 0.12) and not evident in the subterranean species Ch. elongata.

All three species compensated for the vagaries of climate through bet-hedging tactics. Bet-hedging is so pervasive that a recent substantial increase in temperature seems to have a negligible effect on the distribution pattern of all three species. Based on lifehistory data it is conceivable that both soil-inhabiting Choleva species, which require a relatively low thermal sum for their development, were already present in western Europe during the sub-arctic conditions when ice shields reached their maximum extension during glacial periods by shifting their activity from the cold to the warm season. The Atlantic fringe north of the Pyrenees, where the climate was not cold enough for permafrost during glacial stages, was probably the only refuge where Ch. elongata might have survived. In contrast, the Mediterranean region should have been the northernmost refuge for C. nigricans during glacial periods. This species has relatively high day-degree requirements $\left(=1150 \mathrm{~d}^{\circ}\right)$ for individual development when compared to both Choleva species $\left(=700 \mathrm{~d}^{\circ}\right)$.
\end{abstract}

\section{INTRODUCTION}

According to Jeannel (1936), the Cholevinae are a basal group of Staphylinoidea which may have diversified during the Tertiary epoch within the remnants of the Hercynian mountain chains, at least for the numerous species of the genera Choleva and Catops. The cold climate during the Pleistocene would have forced the thermophilous species to retreat to the warmer climates of the south. If it is correct that the Cholevinae did not diversify during the Pleistocene, as is assumed for many other beetles (Coope, 1979), several of the Cholevinae which retreated south during the ice ages should exhibit northward migrations during the interglacial times as documented for many other insects (Holdhaus \& Lindroth 1939; Holdhaus, 1954). The intimate relationship between changes in climate and changes in distribution of species has been well documented, particularly in Great Britain, for the period since the last truly interglacial climatic phase about 120,000 years ago (Coope, 1979). In contrast, the cold climate during the Pleistocene may have forced other species which remained within their area of distribution to search for favourable sites which were sheltered, south- facing, or coastal and relatively frost-free (Delcourt \& Delcourt, 1991).

About 70 different species of Cholevinae are known to live in central and north-western Europe. These species show diverse and remarkable distribution patterns. They can be divided into at least three different groups based on their distributional ranges. One group contains species which are widely distributed in the Palaearctic and range from North Africa to the northernmost areas of Europe (Catops coracinus Kellner, Catops subfuscus Kellner), or which also inhabit the Nearctic and are circumboreally distributed (Sciodrepoides watsoni Spence, Catops alpinus Gyllenhal). A second group is comprised of narrow-ranging species with a restricted distribution pattern in the coldest regions of the Palaearctic. These species live in alpine (Catops ventricosus Weise, Catops joffrei Saint-Claire Deville), boreal (Choleva septentrionis Jeannel, Choleva lederiana Reitter) or boreomountain environments (Catops longulus Kellner). Others are glacial relicts which occur more locally (Choleva vornatcheri Schweiger, Choleva septentrionis holsatica Benick \& Ihss.). A third group includes species which are restricted to the western and central parts of Europe (Catops westi Krogerus, Choleva elongata 
Paykull), which reach highest population densities within this region (Catops nigricans Spence, Choleva agilis Illiger), or which are mainly distributed near the coast (Catops quadraticollis Aubé, Choleva angustata Fabricius).

Insects that live in boreal and in temperate biomes are mainly hampered by low temperatures. In many beetle species the adults are the most resistant of the stages and can survive the adverse cold season in a dormant stage. Consequently they reproduce in spring, thus allowing larval development during the warm summer months.

However, there are several insects which behave in just the opposite way. These insects reproduce and develop during autumn and winter when the temperature is low and spend the warmest months of the year in dormancy (Masaki, 1980). Several species of the subfamily of Cholevinae (Leiodidae) are such "cold season" insects (Topp, 1994). Many of them belong to the third geographical group as classified above.

Species of this third group, which nowadays show a coastal or mainly a western and central European distribution pattern, may have survived unfavourable climatic conditions by choosing adequate habitats within their ranges instead by undergoing extensive migrations between glacial and interglacial phases. We hypothesize that especially the narrow-range species of central and western Europe survived the glacial periods mostly in oceanic and relatively frost-free areas instead of retreating to the south. If our hypothesis is correct, the species should be adapted to low temperatures and additionally be characterized by flexible developmental cycles. Flexibility in developmental cycles for these species should be necessary because organisms living in boreal and temperate regions have to cope with large inter-annual climatic variability.

To test this hypothesis the life-history parameters of three different species of Cholevinae from the third group defined previously were studied in the laboratory under different simulated climatic conditions. The adults of the selected species are active during the winter; however, they differ both in their current distributional range and adaptations to subterranean life.

We addressed the following questions:

1. At which temperature is development optimised in respect to reproduction and survival rate?

2. How many day-degrees are necessary for development from the egg to the reproducing adult?

3. What are the cues for synchronizing the developmental cycle with the seasonal cycle?

4. Are there mechanisms for stabilizing the annual cycle and ensuring development in unpredictable and varying environments?

5. Do the species compensate for the vagaries of climate by employing bet-hedging tactics?

\section{MATERIALS AND METHODS}

Species which start to lay eggs in autumn, which are active during the winter in the adult stage and develop from the egg stage to the adult stage mainly during the winter months, are termed "cold-season" species. The "cold-season" species Catops nigricans Spence exhibits the widest distribution of the three species studied. Adults and larvae of this species were collected in the field at four different sites near the cities of Kiel, Germany $\left(54^{\circ} 22^{\prime} \mathrm{N}, 10^{\circ} 6^{\prime} \mathrm{E}\right)$, Cologne, Germany $\left(50^{\circ} 54^{\prime} \mathrm{N}, 7^{\circ} 6^{\prime} \mathrm{E}\right)$, Paris, France $\left(49^{\circ} 25^{\prime} \mathrm{N}, 2^{\circ} 20^{\prime} \mathrm{E}\right)$ and London, England $\left(50^{\circ} 54^{\prime} \mathrm{N}, 0^{\circ} 6^{\prime} \mathrm{W}\right)$. This species lives mainly in the litter layer of deciduous forests. The beetles Choleva agilis Illiger and Choleva elongata Paykull were also collected near Cologne. Both species have a narrower range of distribution than C. nigricans, are mainly subterranean and live mostly in the nests and burrows of small mammals. The distribution of $C h$. elongata is more restricted than that of $C h$. agilis.

Individuals of all three species were bred in the laboratory in petri dishes lined with filter paper on the bottom and a piece of crumbled cellulose which was about one quarter of the size of the petri dishes. The cellulose was moistened every second or third day and served not only as a source of moisture but also provided the substrate for oviposition. Specimens were fed with mealworm larvae. Half or whole segments of the abdomen, depending of the size of the mealworm larvae, were offered every second or third day as food. Unconsumed food was removed every fourth day to suppress the development of fungi. Nevertheless, propagation of fungi could not be avoided. Because fungi hamper the development of beetles and increase mortality, the individuals were placed in new, sterilized petri dishes every week. Adult beetles were kept as male and female pairs of almost the same age. Eggs were removed every second or third day and kept separately in clusters of up to five eggs each. Parent-offspring relationships were thus known (Topp, 1990).

Beetles were bred at different temperatures and photoperiods. LD (long day) refers to light: dark cycles of $16 \mathrm{~h}: 8 \mathrm{~h}$. SD (short day) refers to light: dark cycles of $8 \mathrm{~h}: 16 \mathrm{~h}$. Photoperiods between LD and SD were chosen to calculate the photoperiodic threshold. DD refers to permanent darkness and means that beetles were reared in incubators in which the temperature regimes were programmed but there was no photophase. However, adults were exposed to full light for about 10 minutes every second or third day.

Choleva elongata develops and spends most of its life in the microcave system of the soil. Some individuals which have been sighted outside of these subterranean habitats may have been relocated there by accident. For example, adult specimens of $C h$. elongata were found between the flotsam after flooding of the nests of moles situated on riverbanks. On the other hand, individuals of $C h$. elongata may disperse for a short time outside of their subterranean habitats to find a mate or an appropriate place for oviposition, as is common for some other insects. This relatively short time interval of dispersion could be under the influence of photoperiod and thus determine the duration of aestivation. To simulate such changing conditions in laboratory, beetles were kept at $10^{\circ} \mathrm{C}, \mathrm{LD}$ for a period of 20,40 , or 60 days and afterwards at $10^{\circ} \mathrm{C}, \mathrm{SD}$.

One might argue that rearing insects under constant environmental conditions is an artificial method which cannot give a natural portrayal of the conditions found in the field. Indeed, from dormancy studies we know that some species respond not only to constant, but also to changing environmental conditions over time (Danks, 1987). Therefore, we also tested fitness values for females of $C$. nigricans when the temperatures and photoperiods changed separately or simultaneously during the life cycle of the adults. For example, a more realistic life cycle with respect to the environmental conditions can be obtained when adults experience diapause at relative high temperatures and under long-day conditions $\left(15^{\circ} \mathrm{C}, 16 \mathrm{~L}: 8 \mathrm{D}\right)$ and reproduce 


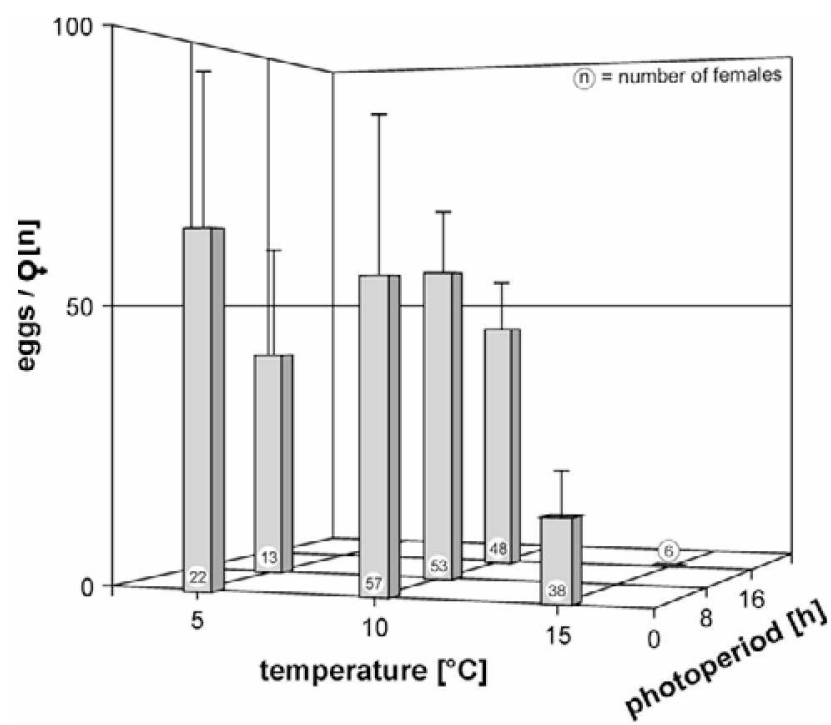

Fig. 1. Fecundity of Choleva agilis (eggs/female, mean \pm S.E.) at different constant temperatures and photoperiods (data from Ehlert et al., 1997).

at relatively low temperatures and under short-day conditions $\left(10^{\circ} \mathrm{C}, 8 \mathrm{~L}: 16 \mathrm{D}\right)$. Using these environmental cues, we indeed obtained increased values for reproduction $(p<0.05)$. However, $10^{\circ} \mathrm{C}$ remained unchanged as the optimal temperature for the reproduction and survival of $C$. nigricans (Topp, 1990).

To study metabolism, measurements of oxygen consumption were carried out in a Warburg apparatus. The specimens were adapted for one week to the varying experimental conditions prior to the measurements (Grigo \& Topp, 1980). Reaction patterns of a cold-season species (Catops nigricans) were compared to those of a warm-season species. Such an example is Sciodrepoides watsoni, which is of almost the same size to $C$. nigricans, breeds in spring, is active during the summer and whose larval development takes places during the warm summer months.

Statistical analyses were carried out using methods given in Sachs (1984). The Student t-test was applied to test for significance. The thermal thresholds for development were obtained by the least-squares method of linear regression. The technique for estimating the heritability of the duration of diapause was taken from Falconer (1989).

\section{RESULTS}

\section{Adaptation to the cold}

\section{Reproduction, development and survival rates}

The life history characteristics of all three cold-season species were similar. Reproductive values of Choleva agilis with respect to different temperatures and photoperiods are given in Fig. 1. Although the reproductive rates of both species were not influenced by photoperiod, the rates were temperature dependent. Highest reproduction rate was found at $5^{\circ}$ and $10^{\circ} \mathrm{C}$ with no significant differences between the two temperatures $(p>0.05)$. This was in contrast to $C$. nigricans, which had its highest reproduction rate at $10^{\circ} \mathrm{C}$ (Topp 1990). In all species, reproduction decreased significantly at $15^{\circ} \mathrm{C}(\mathrm{p}<0.01)$. At this relatively high temperature, both Choleva species were able to reproduce only under DD. For both species, the

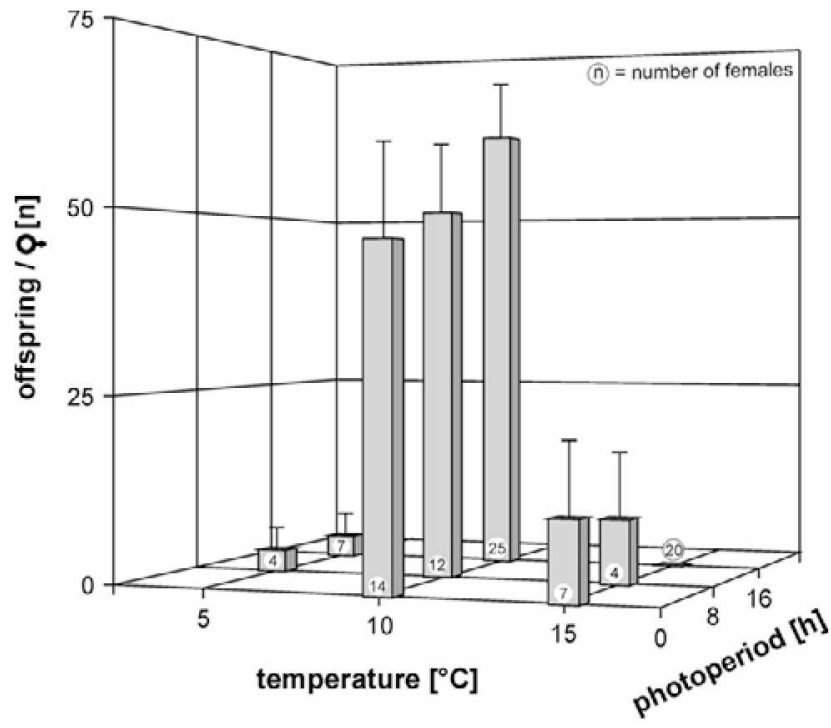

Fig. 2. Replacement rate of Catops nigricans (number of offspring/female, mean \pm S.E.) calculated from laboratory studies at different constant temperatures and photoperiods (data from Topp, 1990).

percentage of surviving pre-imaginal stages was not influenced by temperatures between $5^{\circ}$ to $15^{\circ} \mathrm{C}(\mathrm{p}>0.05)$ or photoperiod.

The replacement rates were calculated according to the following equation: $R_{0}=$ (eggs per eclosed female) $\times$ (percent hatch) $\times$ (percent larvae eclosing as adults) $\times$ (percent fertile females). The highest replacement rates for both Choleva species were obtained at $5^{\circ}$ and $10^{\circ} \mathrm{C}$, with no significant differences in the values between the two temperatures $(\mathrm{p}>0.05)$. In contrast, for $C$. nigricans the highest replacement rates were calculated at $10^{\circ} \mathrm{C}$ (Fig. 2), and were independent of photoperiod at this temperature $(\mathrm{p}>0.05)$; the values calculated for $5^{\circ}$ and $15^{\circ} \mathrm{C}$ were significantly lower $(\mathrm{p}<0.001)$.

The lower thermal thresholds for the developmental stages of all three cold-season species ranged from $+2^{\circ}$ to $-5^{\circ} \mathrm{C}$ (Topp, 1994).

\section{Homeostasis in respect to the duration of diapause}

The duration of adult aestivation in C. nigricans as tested for the Cologne-strain at DD and LD was about $200 \mathrm{~d}$ between $5^{\circ}$ to $15^{\circ} \mathrm{C}$. The duration of this relatively long diapause could be shortened at $10^{\circ} \mathrm{C}, \mathrm{SD}$ (Fig. 3, p < $0.001)$.

In $C h$. agilis the influence of SD on the duration of diapause was significant $(\mathrm{p}<0.05)$, but less pronounced than for C. nigricans (Fig. 3). In Ch. elongata the duration of diapause was not influenced by photoperiod, not even at $10^{\circ} \mathrm{C}(\mathrm{p}>0.05)$. Temperature affected the duration of diapause in the latter species only marginally (Table 1). Homeostasis during diapause in response to external cues such as temperature and photoperiod which otherwise mainly determine development and seasonal timing in ectotherms is an unusual phenomenon. It is unknown from litter-dwelling and phytophagous insects to date. 


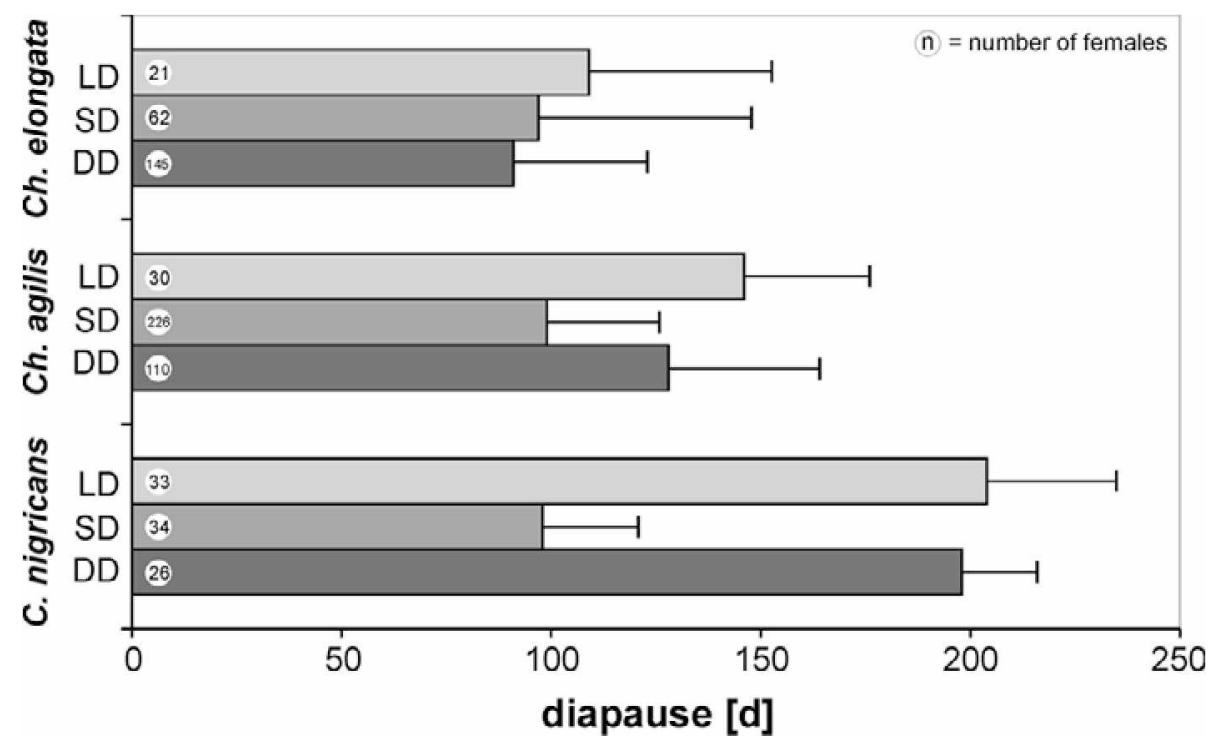

Fig. 3. Effects of photoperiod on the duration of adult diapause (d, mean \pm stand. dev.) in three different species of Cholevinae at $10^{\circ} \mathrm{C}$. The photoperiodic influence diminishes (C. nigricans $>C h$. agilis $>$ Ch. elongata) in parallel from epigeic to endogeic life style.

Further experiments were carried out to test the influence of changing environmental conditions. Sexual pairs of Ch. elongata were first bred at DD, then placed under long-day conditions for 20,40 or 60 days, and finally exposed to short-day or DD. All these experimental designs had no effect on the duration of diapause. Thus, these experiments confirm that exogenic cues do not influence the duration of diapause (Fig. 4).

\section{Heritability of the duration of diapause}

With respect to the duration of diapause, the individuals of all cohorts (here: group of adults of the same age) could exhibit great differences (Fig. 3), even when reared under any single experimental condition. These differences seemed to be somewhat stronger in $\mathrm{Ch}$. elongata than in the other two species.

To evaluate the evolutionary potential of all traits considered, the genetic variation within the species was investigated. A comparison of heritability estimates for life history characteristics measured on wild animals gave an average value of $0.262(\mathrm{n}=341)$ (Mousseau \& Roff, 1987). Our assumption was that the heritability of the duration of adult diapause in Cholevinae will show this average value. The results obtained by daughter-mother regressions for two populations of $C$. nigricans fit this expectation. Both cohorts (Table 2) revealed similar results. The average ranges in the duration of diapause

Table 1. Time period (d) from eclosion of females until first reproduction (duration of diapause, aestivation) for Choleva elongata at different constant temperatures and permanent darkness (DD). Number of females tested, mean, standard deviation and extreme values are indicated.

\begin{tabular}{crrccc}
\hline Temperature $\left({ }^{\circ} \mathrm{C}\right)$ & \multicolumn{1}{c}{$\mathrm{n}$} & mean & stand. dev. & $\min$. & $\max$ \\
\hline 5 & 19 & 146 & 44 & 90 & 236 \\
10 & 145 & 91 & 42 & 20 & 271 \\
15 & 34 & 107 & 49 & 35 & 194 \\
\hline
\end{tabular}

among full siblings of single families were about $70 \%$ of the ranges characterized by the whole cohorts (Topp, 1990). In contrast to C. nigricans the heritability of the duration of diapause observed for both Choleva species was lower than expected. For $C h$. agilis we calculated $\mathrm{h}^{2}$ $=0.12(\mathrm{p}=0.05)$, while the heritability of the length of diapause in $C h$. elongata was not significantly different from zero ( $p>0.05$, Table 2, Fig. 5). Thus, each offspring can be seen as an independent sample of the cohort. The calculations for the three species chosen show that the heritability with respect to the duration of diapause seems to decrease in parallel with decreasing sensitivity to environmental cues and the increasing adaptation to subterranean life.

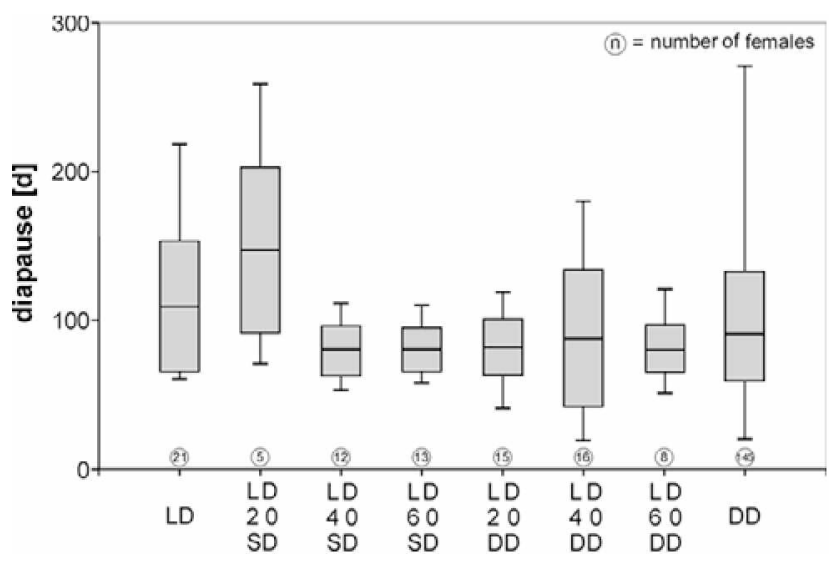

Fig. 4. Duration of diapause (d, mean \pm stand. dev.) in Choleva elongata in respect to changing environments. Adults lived for a time interval of 20,40 or 60 days at LD and at SD or DD thereafter. Duration of diapause was not significantly different $(p>0.05)$ for all experimental designs. Duration of diapause at constant LD and DD are indicated for comparison. These studies confirm the results that the photoperiod does not effect the duration of diapause in this species (see Fig. 3). 
TABLE 2. Heritability (mean, standard error) for the duration of diapause (aestivation) in different strains of Cholevinae. Heritabilities were measured by regressions between dams and single daughters and by weighting the dams according to the number of daughters.

\begin{tabular}{lccccc}
\hline Species & $\begin{array}{c}\text { Families } \\
\text { (n) }\end{array}$ & $\begin{array}{c}\text { Dam- } \\
\text { daughter } \\
\text { values }\end{array}$ & $\mathrm{h}^{2}$ & S.E. & $\mathrm{p}$ \\
\hline $\begin{array}{l}\text { Catops nigricans } \\
\text { (Cologne) }\end{array}$ & 12 & 123 & 0.22 & 0.13 & 0.04 \\
$\begin{array}{l}\text { Catops nigricans } \\
\text { (London) }\end{array}$ & 36 & 235 & 0.26 & 0.09 & 0.01 \\
$\begin{array}{l}\text { Choleva agilis } \\
\text { (Cologne) }\end{array}$ & 65 & 265 & 0.12 & 0.02 & 0.05 \\
$\begin{array}{l}\text { Choleva elongata } \\
\text { (Cologne) }\end{array}$ & 50 & 175 & -0.02 & 0.11 & n.s. \\
\hline
\end{tabular}

\section{Adjustment of the developmental cycles to the season}

The results (Fig. 1, 2) of the studies on cold-season species provide evidence that optimal reproductive success occurs when oviposition takes place at $10^{\circ} \mathrm{C}$ or lower. In the area of study, such low average temperatures occur either in early spring or in autumn during the months of October and November. For this reason the adults search for cool places during the warm season and thus avoid high summer temperatures. Both a selection for a subterranean life or a preference for habitats such as the litter layer of deciduous forests, accompanied by a dormant phase which reduces the metabolism at high temperatures, are successful strategies for survival. Reproduction in autumn should increase life expectancy, because larvae also suffer at high temperatures.

In order to optimise replacement rates, subsequent generations of Cholevinae must reproduce at the same or almost at the same time of the year as the previous generation. The species studied here generally have the same solution to this problem as many other insect species living at high latitudes; they include an obligatory diapause in their developmental cycle just after a feeding period following eclosion. However, because these coldseason species develop during winter and eclose in spring, diapause has evolved as a form of aestivation (Masaki, 1980) instead of hibernation. In aestivating species (as opposed to hibernating ones) the temperature is not an appropriate cue for terminating the duration of diapause.

In $C$. nigricans the duration of adult aestivation is manifested by two different reaction patterns (Topp, 1990). 1) An endogenous component determines the duration of diapause. This reaction pattern is independent of temperature at $\mathrm{DD}$ and $\mathrm{LD}$ in the range from $5^{\circ}$ to $15^{\circ} \mathrm{C}$, however, it depends on temperature at SD. Moreover, the duration of diapause differs between populations living in distinct climates. 2) An exogenous component fine-tunes the individual duration of diapause as determined by the endogenous component to the appropriate seasonal date if necessary. For example, high temperatures $\left(\geq 16^{\circ} \mathrm{C}\right)$ in combination with LD conditions delay the date of oviposition, and short days in combination

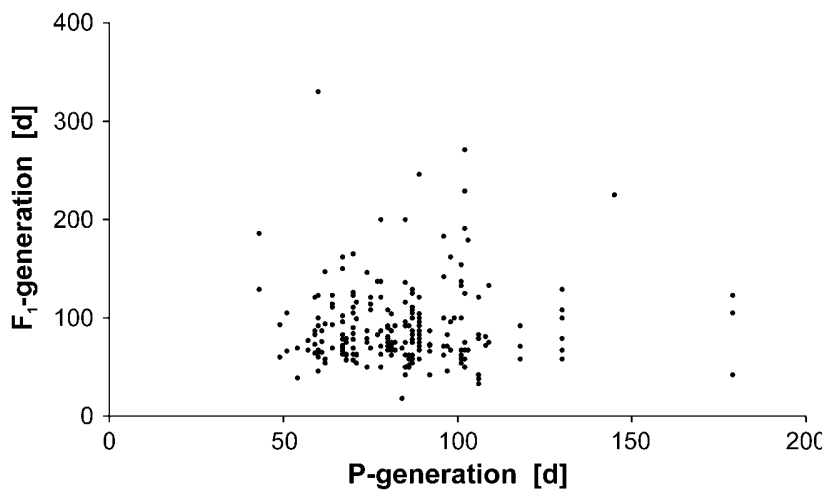

Fig. 5. Dam-daughter values for the duration of adult diapause in Choleva elongata. In contrast to the other species tested there was no significant daughter-on-dam regression for this species (see Table 2).

with low temperatures $\left(\leq 10^{\circ} \mathrm{C}\right)$ advance the date of oviposition.

Fig. 6 represents the duration of diapause for all four cohorts of $C$. nigricans, studied at $10^{\circ} \mathrm{C}$ at LD and SD. Short-day conditions (8L : 16D) always resulted in a shorter duration of diapause than long-day conditions (16L : 8D). Regarding the absolute duration of diapause under either condition, the shortest values were found for the Kiel-strain and the longest values for the Paris-strain.

Another question was: Is the duration of diapause important for more than achieving an optimal date for reproduction? To obtain an answer, we calculated the developmental cycles according to the reaction norms for the developmental stages as found in the laboratory, with respect to the field temperature and photoperiodic conditions (mean monthly temperatures and photophases including civil twilight). By adding the duration of adult diapause and the development time for the pre-imaginal stages (Topp, 1990; Ehlert et al., 1997), we found that most individuals of the cohorts of $C$. nigricans and $C h$. agilis (but not of Ch. elongata) were almost perfectly adjusted to the seasonal cycle. Fig. 7 represents the phenology of average individuals of four cohorts of C. nigricans living at different locations under the average climatic influence. The individual cycles were adjusted so perfectly to the season that the endogenous component which determines the duration of diapause was usually sufficient to guarantee an optimal seasonal development for most individuals of a cohort. Tuning the duration of diapause with exogenous factors was only necessary for those beetles which strongly deviated from the average.

However, the values of the London-cohort of $C$. nigricans deviated from the values of the continental cohorts not only in the duration of diapause as shown in Fig. 6 but the photoperiodic threshold was also different. The photoperiodic responses of the continental cohorts showed a threshold at $14 \mathrm{~h} 10 \mathrm{~min}$, whereas the Londoncohort had evolved a photoperiodic threshold at 13 h 15 min (Fig. 8). Consequently, the London-cohort will be influenced by a prolonged period of long-day conditions during the course of the year. Lowering the photoperiodic threshold while increasing the duration of diapause is 


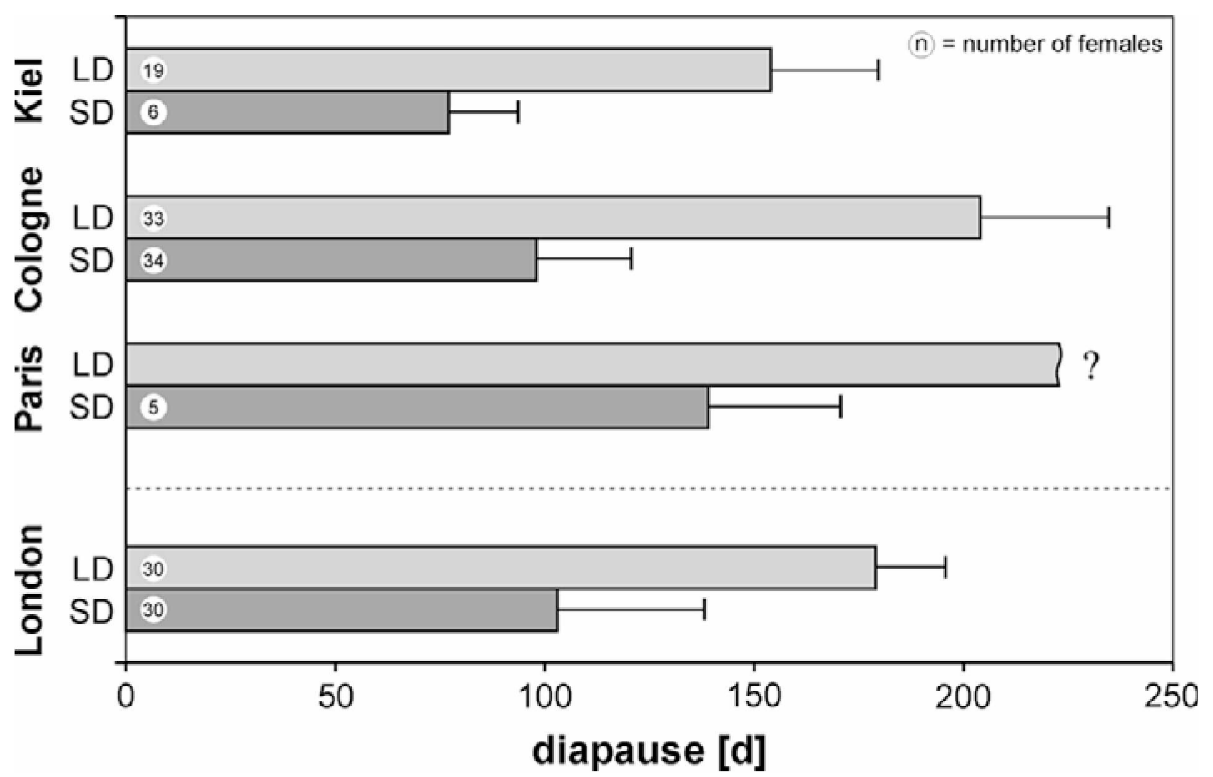

Fig. 6. Duration of diapause (d, mean \pm stand. dev.) measured from adult eclosion until the age at first reproduction (aestivation) at $10^{\circ} \mathrm{C}$ and different photoperiods ( $\mathrm{SD}=8 \mathrm{~h}$ light $: 16 \mathrm{~h}$ dark, $\mathrm{LD}=16 \mathrm{~h}$ light $: 8 \mathrm{~h}$ dark) for four different cohorts of $C$. nigricans. For the continental cohorts, the duration of diapause increased when winter temperatures decreased. The London cohort demonstrates an exception because of an alternated photoperiodic threshold (see Fig. 9) (data from Engler, 1982; Topp, 1990; Brett 1994).

seen as being an adaptation to a warmer climate, especially in winter. The prolonged influence of LD generally increases the duration of diapause which helps to adjust the developmental cycle to the seasonal cycle when preimaginal development time is shortened by elevated winter temperatures. The slopes of both photoperiodic response curves shown in Fig. 8 were the same in terms of the values of Boltzmann sigmoidal equations. This means that the selection pressure of photoperiod on the

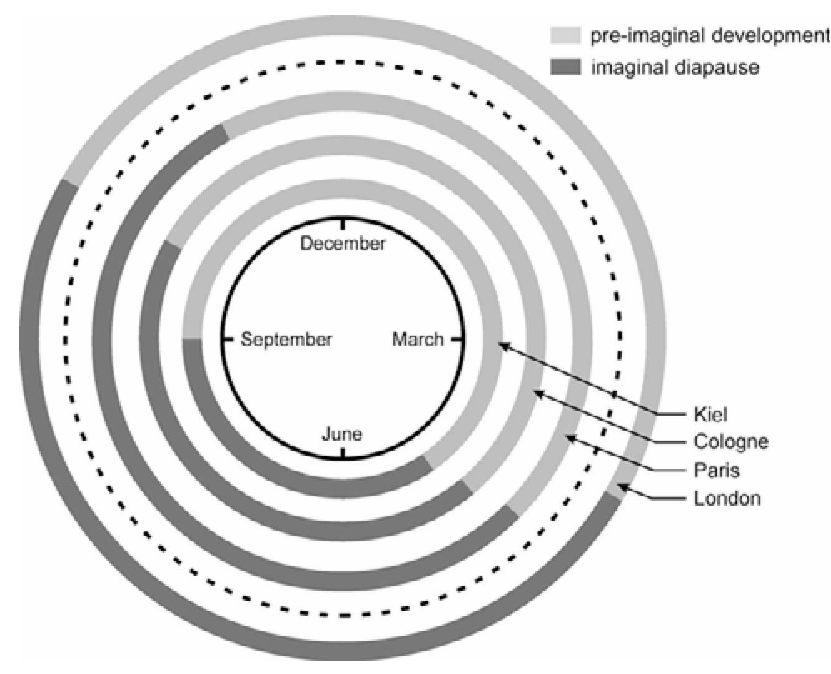

Fig. 7. Adjustment of the developmental cycle of the average individual of the three continental cohorts and a cohort originating from Great Britain of Catops nigricans to an average seasonal cycle in that specific area. Winter temperatures determine the duration of pre-imaginal development and select for the optimal duration of imaginal diapause in order to achieve the developmental cycle within the seasons. The individuals of the London-cohort exhibited a photoperiodic threshold different from that of the continental strains (see Fig. 8). duration of diapause does not differ between the two cohorts.

The developmental cycle did not adjust to the seasonal cycle for the average $C h$. elongata specimen. The development time of all pre-imaginal stages (which depended on temperature and partly on photoperiod, see Fig. 9) added to the duration of adult diapause (which did not depend on temperature and photoperiod, see Table 1, Figs $3,4)$ was shorter than 365 days when calculated for environmental conditions. This means that only single individuals of the Ch. elongata cohort $(<50 \%)$ were perfectly adjusted to the seasonal cycle, at least in terms of the present average climatic conditions occurring at the collection site.

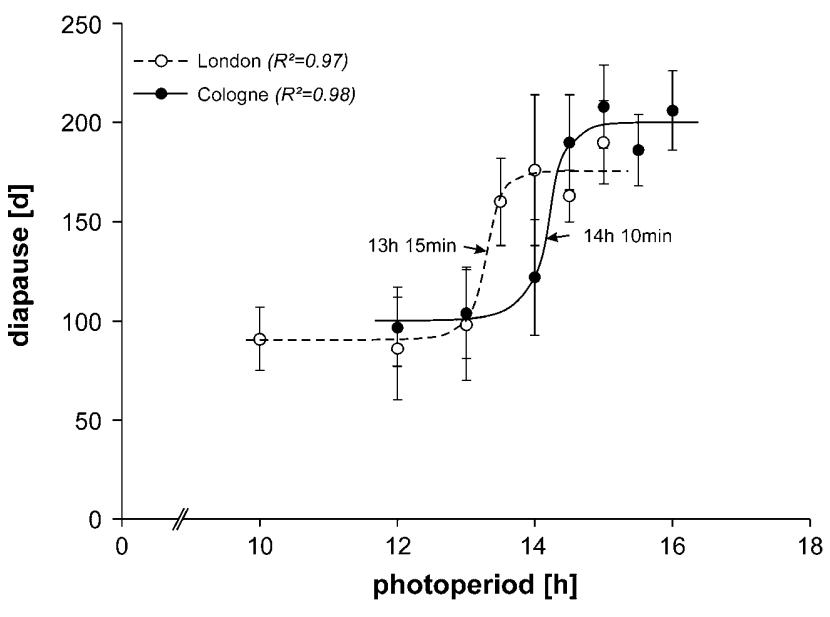

Fig. 8. Photoperiodic thresholds calculated from the duration of diapause ( $\mathrm{d}$, mean \pm stand. dev.) at different photoperiods shown by Catops nigricans cohorts originating from Cologne and London (data from Topp, 1990; Brett, 1994). 


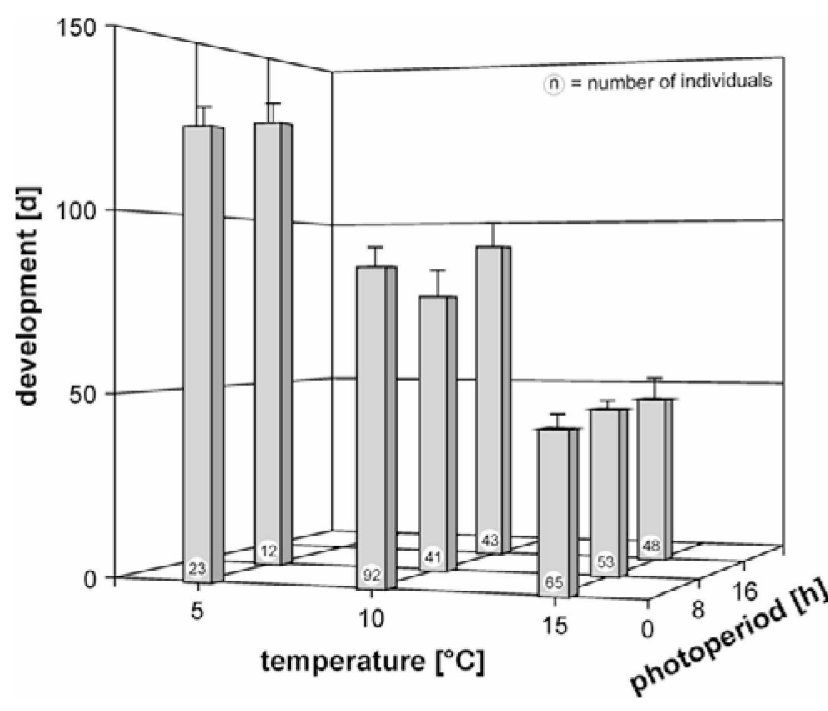

Fig. 9. Duration of the pre-imaginal development in Choleva elongata (mean \pm stand. dev.) in respect to different temperatures and photoperiods. Temperature mainly determines developmental rate. However, at $10^{\circ} \mathrm{C}$ photoperiod also affects development (SD vs. LD, $\mathrm{p}<0.01)$

\section{Metabolism at low temperatures}

The circumboreal-living Sciodrepoides watsoni is a warm-season species with a wide distribution pattern including habitats north of the polar circle. It is a spring breeder which can reproduce successfully at relatively high temperatures of $\geq 16^{\circ} \mathrm{C}$ and under long day conditions (16L : 8D). Individuals of a population originating from northern Germany terminated reproduction at temperatures of $\leq 10^{\circ} \mathrm{C}$. Larval mortality was also much higher at this low temperature (Engler, 1982). The metabolic rate of adult $S$. watsoni was found to be temperature-dependent (Fig. 10) as expected for ectothermic organisms (Precht et al., 1973). The individuals exhibited $Q_{10}$ values of about 4 (Engler, 1982).

Metabolism of the cold-season $C$. nigricans is independent of temperature. The metabolic values shown here (Fig. 10) apply to females during the phase of reproduction, i.e. long-day conditions (16L : 8D) for $S$. watsoni and short-day conditions (8L : 16D) for C. nigricans. Metabolic rates of both species decreased by about $50 \%$ at all temperatures if the adults were in the dormant stage (Engler, 1982). This means that homeostasis as observed for C. nigricans (Fig. 10) is maintained in dormant as well as in non-dormant stages. Moreover, Fig. 10 shows us, assuming that nutrition is not the limiting factor, that low temperatures (below a threshold of ca. $12^{\circ} \mathrm{C}$ ) will be advantageous but high temperatures disadvantageous for a "homeostatic beetle" when compared to a beetle characterised by a temperature-dependent reaction pattern.

\section{Adaptation to variable environments \\ Bet-hedging at the age of first reproduction}

The comparative studies of $C$. nigricans with individuals originating from different cohorts always represented a perfect adaptation of the average specimen to the

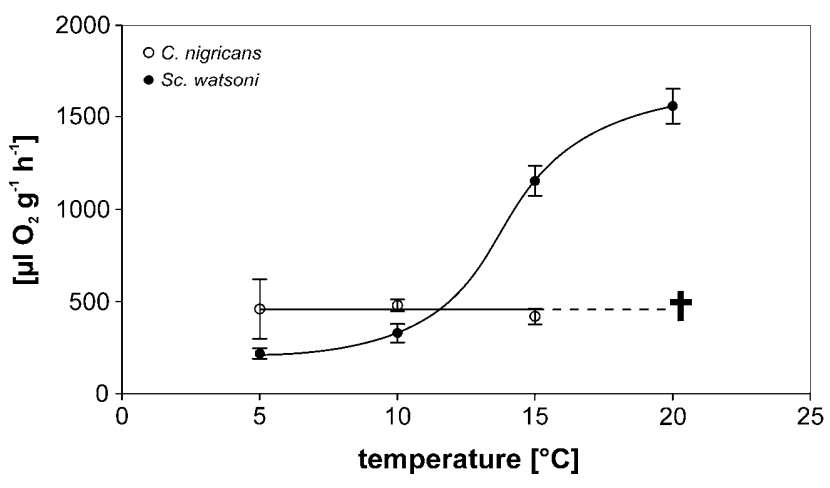

Fig. 10. Adult metabolism ( = oxygen consumption, mean \pm stand. dev.) of the warm-season species Sciodrepoides watsoni and the cold-season species Catops nigricans. Metabolic rates of the non-diapausing adults, i.e $S$. watsoni at long-day and $C$. nigricans at short-day conditions are compared. The metabolic rates of diapausing adults were reduced to about $50 \%$ of the data shown here (data from Engler, 1982).

average climate (Fig. 7). However, organisms that live in boreal and temperate biomes must not only cope with extensive changes in the seasonal climate but also with inter-annual climatic variability (Furgeson \& Messier, 1996). Much of life history theory has concentrated on explaining and predicting variation in the development of organisms (Stearns, 1992). A general result is that genotypes are expected to show flexibility in life history characteristics in response to the often unpredictable variations in environmental conditions. Spreading the age of first reproduction within families is interpreted as a bet-hedging mechanism to cope with the vagaries of weather conditions in an unpredictable environment.

In earlier studies on Cholevinae, exemplified by $C$. nigricans (Topp, 1990) and Ch. agilis (Ehlert et al., 1997), the temporal spreading of reproduction of the species was used to calculate the possible outcomes for development under field conditions. These calculations were based on average monthly temperatures of the last 30 years and on day-length including civil twilight. The data shows that at least some siblings of all families were able to match the optimal date of reproduction in subsequent generations. For both species there were only two situations for which the synchronisation of the developmental cycle with the season failed. These situations occurred (a) when descendants hatched when their mothers were very young (i.e. relatively early in the season), and (b) when individuals grew at extremely high winter temperatures. Under these circumstances oviposition was generally attained during a time interval before the optimal date of reproduction. However, even then an ecological fine-tuning, primarily by photoperiod but additionally by temperature, helped at least some of these individuals to match the optimal date for reproduction. Others that suffer under a "genetic load" contribute to reduce replacement rates. On the other hand, individuals possesing a genetic load under present climatic conditions will be extremely successful under circumstances of climatic changes. 
TABLE 3. Life expectancy, duration of oviposition and number of eggs per female (mean \pm S.D.) obtained at $10^{\circ} \mathrm{C}$, DD for different Cholevinae originating from Cologne.

\begin{tabular}{lccrr}
\hline Species & $\mathrm{n}$ & $\begin{array}{c}\text { Life } \\
\text { expec- } \\
\text { tancy }\end{array}$ & $\begin{array}{c}\text { Duration } \\
\text { of oviposi- } \\
\text { tion }\end{array}$ & eggs/female \\
\hline Catops nigricans & 12 & $189 \pm 78$ & $98 \pm 32$ & $78 \pm 43$ \\
Choleva agilis & 11 & $299 \pm 225$ & $191 \pm 48$ & $153 \pm 85$ \\
Choleva elongata & 42 & $341 \pm 135$ & $207 \pm 99$ & $86 \pm 58$ \\
\hline
\end{tabular}

In contrast to $C$. nigricans and Ch. agilis, the developmental cycle of most $\mathrm{Ch}$. elongata individuals failed to match the seasonal cycle when average monthly temperatures were used for calculations. (The low percentage of a cohort adapted to the seasonal cycle can give an explanation of the low population density of this species in the field which is much lower than those of both other Cholevinae mentioned). Moreover, adults of $\mathrm{Ch}$. elongata, because of their homeostatic response during diapause with respect to photoperiod and temperature, did not have the possibility of an ecological tuning. In addition, the failing genetic influence on the duration of diapause (Fig. 5) excludes a selection to changing environments. Ch. elongata obviously compensates for this failure at least partly by spreading the date of first reproduction more widely than the other two species (Fig. 3 ). On the other hand, deviations from the circannual cycle will be less disadvantageous because this beetle is a truly soil-inhabiting species, living in a subterranean environment in which climatic fluctuations are lower than for litter-dwelling species living on the forest floor.

\section{Semelparity versus iteroparity}

As weather is unpredictable, the best way to cope is to spread the ovipositing process around the date which was best for the previous generation. It is also benefical when females do not put their eggs into one basket, ovipositing instead over a long time interval. Table 3 summarizes life expectancy, time interval of oviposition and fecundity of the three Cholevinae species at $10^{\circ} \mathrm{C}$, DD. These characteristics were lowest for $C$. nigricans, a species which is truly semelparous in the field. Females reproduce from October until January when they remain in permanent darkness in the microcaves of the soil. However, when they leave their caves for the litter layer of the forest floor and are under the influence of light regimes, reproduction may be terminated after only two months of oviposition in November (Topp, 1990). The life expectancy and time interval of oviposition for both Choleva species exceeded the values for $C$. nigricans. Both characteristics were so extended in Ch. elongata that we assume that at least some individuals are iteroparous in the field. Ch. elongata lowers its oviposition rate in order to extend the duration of oviposition. The reproductive potential of the litterdwelling $C$. nigricans and the subterranean $C$. elongata were not significantly different $(p>0.05)$.

\section{DISCUSSION}

\section{Global warming}

Many insect species are known to regulate their life cycles in response to environmental cues such as photoperiod or temperature (Danks, 1987). The responses serve to synchronize developmental stages resistant to a particular season and favour oviposition at time intervals which maximize their reproductive success. The date of reproduction is a risk, involving either post-breeding mortality or reductions in growth and hence in future fecundity. The optimal age of first reproduction depends on the specifics of this trade-off and also on environmental circumstances. From an evolutionary point of view, it is expected that an organism will respond to all environmental variations in such a manner as to maximize fitness.

There is a considerable body of information on the intra- and interspecific geographic variation of various life-history parameters of insects (Danks, 1987, 1994). These studies suggest that abiotic factors are of crucial importance in determining species distribution and range limits. Most recently, there has been much debate over the possible effects of global climate change on biological systems. For example, climatic records from 20 weather stations in Austria during the last 30 years reveal a significant increase in mean annual temperature of $0.72^{\circ} \mathrm{C}$, mean annual minimum temperature $\left(0.80^{\circ} \mathrm{C}\right)$ and winter temperature $\left(2.36^{\circ} \mathrm{C}\right)$ (Hasenauer et al., 1999).

There is no doubt that the Cholevinae studied are sensitive to these increasing temperatures leading to $C$. nigricans and $C h$. agilis ovipositing later in the season if autumn temperature increases. If adult eclosion occurs at an earlier date in the following year, although the preceding pre-imaginal development started later in the season (this happens when winter temperature increases), selection to a prolonged duration of diapause will maintain a circannual developmental cycle and maximize replacement rate. Moreover, at elevated temperatures individuals characterized by a prolonged intrinsic duration of diapause, which represents a load on the climatic conditions as they are now, will be favoured. As a consequence, if the temperature increases continuously (as has been documented over the last 30 years) there will be no impact on the developmental success of the two Cholevinae $C$. nigricans and $C h$. agilis, at least in western and central Europe.

Higher temperatures will reduce average replacement rates and population density of $C h$. elongata living in western and central Europe. As diapause does not respond to external cues (Fig. 4) and because there is no selection on the duration of diapause (Table 2), the reproductive success of the individuals of the cohort is determined exclusively by their bet-hedging tactics. Rising temperatures will minimize the number of individuals which are able to synchronize the developmental cycle with the seasonal cycle. Thus, if global warming takes place, the only way for Ch. elongata to survive would be to move eastward or to settle in areas of higher elevation, 
where winter temperatures are colder and consequently pre-imaginal development is slowed down.

\section{Maintaining univoltine development at lowered temperatures}

The variations in temperature were much greater during pre-historic times and particularly during the Pleistocene than during the last 30 years (Cox \& Moore, 1993). We posed the question: What are the limits of the phenotypic plasticity which still allow successful development in altered environmental conditions? From temperature studies in a Greenland ice core it has been estimated that the Younger Dryas came to an abrupt end 10,720 years ago and was followed by a warming of about $7^{\circ} \mathrm{C}$ over only 50 years (Dansgaard et al., 1989). Results from the Greenland ice-core project also indicate that the glacial stages were about $12-13^{\circ} \mathrm{C}$ colder than at present (Johnsen et al., 1992). Temperature fluctuations of this size in Greenland must have been associated with significant environmental changes in the entire North Atlantic region and probably also over north-western (Grootes et al., 1993) and southern Europe (Allen et al., 1999).

Using the life-history model for cold-season species (Topp, 1990; Ehlert et al., 1997), we simulated an abrupt drop of $12^{\circ} \mathrm{C}$ for all average monthly temperatures as measured recently in the areas from which the cohorts originate and calculated its effect on the developmental cycle of the species studied.

Siblings of all dams with a shorter duration of aestivation and a younger age of reproduction, characteristics which represent a load for the population under the current climatic conditions, will be favoured if the temperature declines. Finally, the short duration and low heat budget of Arctic summers will favour those adults which are able to reproduce during the spring and allow larvae to develop during summer months.

In C. nigricans, and to a lesser extent also in Ch. agilis, two factors contribute to maintaining optimal fitness at reduced temperatures, a short aestivation period and a selection to a younger age of first reproduction.

A similar selection pattern has evolved in the winter moth Operophtera brumata. This species determines the correct date for reproduction by varying the intrinsic duration of the pupal aestivation period with respect to environmental factors which occur during the cold season. This strategy not only enables the winter moth to live in the temperate zone but also to survive in the subarctic conditions north of the polar circle. For example, in western Europe where harsh winter temperatures usually only exist for a short period, individual hatching occurs early in the season and the pupal aestivation has to be long to allow a developmental synchronisation with the season (Topp \& Kirsten, 1991). In contrast, in northern Europe where harsh winter temperatures last longer, individual hatching occurs late in the season and a short pupal aestivation serves to optimise the date of reproduction in autumn (Peterson \& Nilssen, 1998).

There is no need for Ch. elongata to search for colder conditions if the temperature declines. This species is predisposed to lowered temperatures in order to maintain univoltine development by using two different strategies of bet-hedging: a) high phenotypic plasticity in the duration of aestivation, and $b$ ) extended range in oviposition found between siblings. Both strategies should enable at least some descendants of each dam and in each year to respond in an optimal way.

\section{Activity at low temperature}

Insect growth, development, and fecundity depend mostly on temperature. As a compensation for consistently low temperatures, elevation of metabolism has been invoked as an adaptive response. These adaptations allow activity and development to occur at temperatures lower than possible for non-cold-adapted species (Strathdee \& Bale, 1998). Elevation of metabolism in insects has often been coupled to a presumed need to maintain high growth rates over the short growing season found in cold environments. One of the best examples of such increased respiratory rates at low temperatures comes from Antarctic Acari (Block \& Young, 1978). However, it is by no means agreed that such elevation of rates is common in insects. For example, Myrmica ants show no evidence of metabolic cold adaptation. Individuals from southern latitudes, when adapted to low temperatures, were metabolically even more active than those from more northerly latitudes (Nielsen et al., 1999). It currently seems impossible to determine whether metabolic cold adaptation is a common or a relatively rare phenomenon (Chown \& Gaston, 1999).

The term "metabolic cold adaptation" or "temperature compensation" has been extended to the idea that the metabolic rate of species living in higher latitudes should be less sensitive to temperature than that of lower latitude species (Sømme \& Block, 1991). An analogy presumably can be found between species which live in the same habitat but are active either in the cold or in the warm months of the year. The standard metabolism of the coldseason rove beetle Anthobium atrocephalum Gyll. from the temperate zone is documented as being independent of temperature (Grigo \& Topp, 1980), as it also is for the Antarctic beetle Perimylops antarctica Müller (Block, 1981). The advantage of this strategy for cold-season species is two fold: 1) At lower temperatures, the standard metabolism is elevated compared to that of warm-season species of almost the same size. This elevation may allow the cold-season beetle to be quicker than the warm-season species at the same environmental temperature. 2) At higher temperatures the standard metabolism is lower than that of warm-season species, a fact which can help to save energy during aestivation at relatively high temperature (Fig. 10).

The evolution of homeostasis is believed to be an important factor in allowing animals to venture from physiologically friendly environments into environments hostile to life processes. I suggest that homeostasis in insects living in the temperate zone is a feasible prerequisite for using the cold season for oviposition and development instead of the warm season. However, the measurement of whole-organism oxygen consumption as 


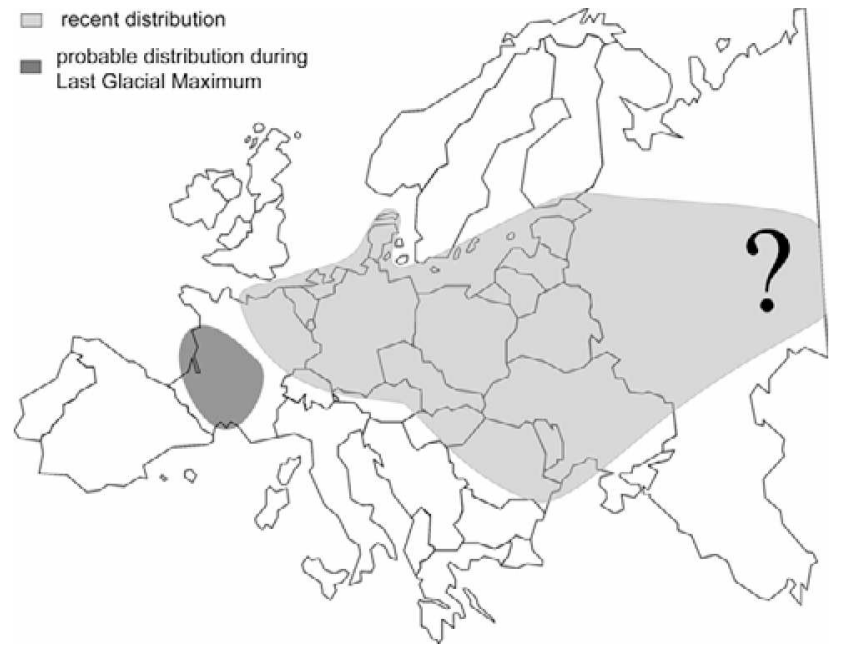

Fig. 11. Recent distribution of Choleva elongata (hatched area) and probable distribution pattern, based on thermal requirements and life-history data, at glacial stages during maximum glaciation (cross-hatched area).

an indicator of individual performance has been criticised (Clarke, 1993).

\section{Refuge during glaciations}

The Arctic growing season is typically 600 or fewer day-degrees above $0^{\circ} \mathrm{C}$ (Strathdee \& Bale, 1998). These low temperatures do not allow the Cholevinae studied to maintain a univoltine developmental cycle. Both Choleva species require about $700 \mathrm{~d}^{\circ}$ above $0^{\circ} \mathrm{C}$ for their development, a number which only marginally exceeds the value of Arctic environments. Temperature demands calculated for $C$. nigricans are higher and reach about $1150 \mathrm{~d}^{\circ}$ above $0^{\circ} \mathrm{C}$ (Topp, 1994).

Based on life-history models (Ehlert et al., 1997) and temperature calculations for the Pleistocene, it is estimated that both Choleva species could have survived the glacial stages at the Atlantic fringe of western France, an area which was almost identical to the maritime tundra and the maritime forest provinces of the Weichselian glacial stage (West, 1977) where winters were not cold enough for permafrost (Fig. 11). This area, which probably was the only refuge of $C h$. elongata, is also seen as a refuge for the birch Betula pubescens (Walter \& Straka, 1970). Choleva agilis may also have survived south of the Pyrenees and the Alps; for C. nigricans, because of its relatively high day-degree requirements for individual development, the Mediterranean region should have been the northernmost refuge during glacial stages.

Choleva elongata and several other cold-season Cholevinae cannot presently be found in the plains of south-western France. We assume that the metabolic costs of an extremely long aestivation, which is necessary in order to maintain a circannual developmental cycle because of the accelerated pre-imaginal development, does not allow such species to survive in these warm climates.

In harsh environments, as apparently occurred during the glacial stages in western Europe, insects are faced with further problems. One problem is the low temperature, another could be the aridity in loess deserts, and a third is a low food supply. The Cholevinae may have solved all three problems. Cold-season species are found to be intolerant to freezing and have slight supercooling ability (Topp, 1978). Some of them appear on snow during the relatively high daytime temperatures in midwinter, even in northern regions such as in Norway, but seek protection below the surface when the temperature drops (Sømme, 1982). Choleva may similarly have survived in sub-glacial environments. The species studied are also active under snow cover and retreat to deep soil layers in order to escape from unpleasant physical conditions such as low temperature and high water vapour pressure deficiencies. Nests of small mammals serve as an appropriate environment (Tasch \& Topp, 1991).

Cholevinae have a broad diet similar to that of the Tenebrionidae which successfully invaded arid environments. They are scavengers which feed on dead insects, carcasses or decaying plant material. Larval development is even successful when the nutrition is restricted to the faeces of small mammals (Engler, 1982). We assume that the main food source of the cold season Cholevinae are the dying insects (mainly adult Nematocera) which suffer from the low temperatures during winter months. It is unlikely that Cholevinae suffer from nutritional deficiencies during winter months when temperature is low.

ACKNOWLEDGEMENTS. This study was supported by DFG. Fred Bartlett and Steve Coulson kindly gave linguistic comments.

\section{REFERENCES}

Allen J.R.M., Brandt U., Brauer A., Hubbertsen H.-W., Huntley B., Keller J., Kraml M., Mackensen A., Mingram J., Negendank J.F.W., Nowaczyk N.R., Oberhäsli H., Watts W.A., Wulf S. \& ZoltTsChKA B. 1999: Rapid environmental changes in southern Europe during the last glacial period. Nature 400: 740-743.

Block W. \& Young S.R. 1978: Metabolic adaptations of Antarctic terrestrial microarthropods. Comp. Biochem. Physiol. 61A: 363-368.

BLock W. 1981: Respiration studies on some South Georgian Coleoptera. Coll. Ecosyst. Subantarctiques 51: 183-192.

BRETT B. 1994: Adaptationsmechanismen - Jahreszeitliche Entwicklung, Phänotypische Plastizität and Heritabilität - bei Ausgewählten, Winteraktiven Choleviden (Insecta: Coleoptera) an ihren Lebensraum. Ph. D. Universität zu Köln, 191 pp.

Chown S.L. \& Gaston K.J. 1999: Exploring links between physiology and ecology at macro-scales: the role of respiratory metabolism in insects. Biol. Rev. 74: 87-120.

ClaRke A. 1983: Seasonal acclimatization and latitudinal compensation in metabolism: Do they exist? Funct. Ecol. 7: 139-149.

Coope G.R. 1979: Late Cenozoic fossil Coleoptera: Evolution, biogeography, and ecology. Annu. Rev. Ecol. Syst. 10: 247-267.

Cox C.B. \& Moore P.D. 1993: Biogeography: an Ecological and Evolutionary Approach, $5^{\text {th }}$ edn, Blackwell Scientific Publications, Oxford, $326 \mathrm{pp}$.

Danks H.V. 1987: Insect Dormancy: An Ecological Perspective. Biological Survey of Canada, Ottawa, $439 \mathrm{pp}$. 
DANKS H.V 1994: Diversity and integration of the life-cycle polymorphism. In: Danks H.V. (ed.): Insect Life-Cycle Polymorphism. Kluwer Acad. Publ., den Haag, pp. 277-312.

Dansgaard W., White J.W.C., \& Johnsen S.J. 1989: The abrupt termination of the Younger Dryas climate event. Nature 339 $532-534$.

Delcourt H.R. \& Delcourt P.A. 1991: Quarternary Ecology: A Palaeecological Perspective. Chapman \& Hall, London, 242 pp.

Ehlert R., Topp W., Thiemermann S. \& Brett B. 1997: Phenotypic plasticity in Choleva agilis to maintain fitness in an unpredictable environment (Coleoptera: Cholevidae). Entomol. Gener. 21: 145-159.

ENGLER I. 1982: Vergleichende Untersuchungen zur jahreszeitlichen Einpassung von Catopiden (Col.) in ihren Lebensraum. Zool. Jb. Syst. 109: 399-432.

FALCONER D.S. 1989: Introduction to Quantitative Genetics, $3^{\text {rd }}$ ed, Longman Scientific \& Technical, New York, 438 pp.

Ferguson S.H. \& Messier F. 1996: Ecological implications of a latitudinal gradient in inter-annual climatic variability: a test using fractal and chaos theories. Ecography 19: 382-392.

Grigo F. \& Topp W. 1980: Einfluß von Adaptationstemperatur und Photoperiode auf den Sauerstoffverbrauch bei Staphyliniden (Col.) in Diapause und Non-Diapause. Zool. Anz. 204: 19-26.

Grootes P.M., Sturver M., White J.W.C., Johnsen S. \& Jouzel J. 1993: Comparison of oxygen isotope records from the GISP2 cores. Nature 366: 552-554.

Hasenauer H., Nemani R. R., Schadauer K. \& Running S.W 1999: Forest growth response to changing climate between 1961 and 1990 in Austria. Forest Ecol. Manag. 122: 209-219.

Holdhaus K. \& LindRoth C.H. 1939: Die europäischen Koleopteren mit boreoalpiner Verbreitung. Ann. Naturhist. Museum Wien 50: 123-293.

Holdhaus K. 1954: Die Spuren der Eiszeit in der Tierwelt Europas. Abh. Zool. Bot. Ges. Wien 18, Universitätsverlag Wagner, Innsbruck, $493 \mathrm{pp}$.

Jeannel R. 1936: Monographie des Catopidae. Paris, Editions du Muséum, Mem. Mus. Nat. d'Hist. Natur. 1: 433 pp.

Johnsen S.J., Clausen H.B., Dansgaard W., Funher K., Gundestrup N., Hammer C.U., Iversen P., Jouzel J. \& Stauffer B. 1992: Irregular glacial interstadials recorded in a new Greenland ice core. Nature 359: 311-313.

Masaki S. 1980: Summer diapause. Annu. Rev. Entomol. 25 $1-25$.

Mousseau T.A. \& Roff D.A. 1987: Natural selection and the heritability of fitness components. Heredity 59: 181-197.
Nielsen M.G., Elmes G.W. \& Kipyatkov V.E. 1999: Respiratory $\mathrm{Q}_{10}$ varies between populations of two species of Myrmica ants according to the latitude of their sites. J. Insect Physiol. 45: 559-564.

Peterson N.A. \& Nitssen A.C. 1998: Late autumn eclosion in the winter moth Operophtera brumata: compromise of selective forces in life-cycle timing. Ecol. Entomol. 23 : 417-426.

Precht H., Laldien H. \& Havsteen B. 1973: The normal temperature range. In: Precht H., Christophersen J., Hensel H. \& W. Larcher (eds): Temperature and Life. Springer, Berlin, pp. 302-354.

SACHS L. 1984: Angewandte Statistik, $6^{\text {th }}$ ed.Springer, Berlin, $552 \mathrm{pp}$.

Sømme L. 1982: Supercooling and winter survival in terrestrial arthropods. Comp. Biochem. Physiol. 73A: 519-543.

SøMme L. \& Block W. 1991: Adaptations to alpine and polar environments. In: Lee R.E. \& Denlinger D.L. (eds): Insects at Low Temperature. Chapman \& Hall, London, pp 318-359.

STEARns S.C. 1992: The Evolution of Life Histories. Oxford University Press, New York, $248 \mathrm{pp}$.

Strathdee A.T. \& Bale J.S. 1998: Life on the edge: Insect ecology in Arctic environments. Annu. Rev. Entomol. 43: 85-106.

TASCh P. \& TopP W. 1991: Überleben mit Insektivoren. Der Entwicklungszyklus des Kurzflüglers Quedius ochripennis Mèn.(Col., Staphylinidae). Zool. Jb. Syst. 118: 359-375.

TopP W. 1978: Untersuchungen zur Kälteresistenz bei Staphyliniden (Col.). Zool. Anz. 201: 397-402.

TOPP W. 1986: Imaginal aestivation in the rove beetle species Omalium rivulare (Coleoptera: Staphylinidae). Entomol. Gener. 12: 51-55.

Topp W. 1990: Selection for an optimal monovoltine life cycle in an unpredictable environment. Studies on the beetle Catops nigricans Spence (Col.: Catopidae). Oecologia 84: 134-141.

TopP W. 1994: Seasonal time partitioning and polymorhism in the developmental cycles of sympatric Staphylinoidea (Coleoptera) living in unstable environment. In: Danks H.V. (ed.): Insect Life-Cycle Polymorphism. Kluwer Acad. Publ., den Haag, pp 277-312.

TOPP W. \& Kirsten K. 1991: Synchronisation of pre-imaginal development and reproductive success in the winter moth, Operophtera brumata L. J. Appl. Entomol. 111: 137-146.

WALTER H. \& STRAKA H. 1970: Arealkunde. Floristischhistorische Geobotanik. Ulmer, Stuttgart, $478 \mathrm{pp}$.

WeSt R.G. 1977: Pleistocene Geology and Biology, $2^{\text {nd }}$ edn. Longman, London, $440 \mathrm{pp}$.

Received August 26, 2002; revised October 21, 2002; accepted December 4, 2002 